Jurnal Kesehatan Masyarakat

\title{
Assessing the Quality of Life Among Commuting Workers and Uncomfortable Travel
}

David Kusmawan $^{1 凶}$, Shofi Andari ${ }^{2}$, Indri H. Susilowati ${ }^{3}$

${ }^{1}$ Occupational Health and Safety Program, Faculty of Medicine and Health Science, Universitas Jambi

${ }^{2}$ Bioinformatics and Computational Biology Graduate Program, Iowa State University, USA

${ }^{2}$ Department of Statistics, Faculty of Mathematics, Computation, and Data Science,

Institut Teknologi Sepuluh Nopember (ITS), Surabaya

${ }^{3}$ Occupational Health and Safety Department, Faculty of Public Health, Universitas Indonesia

\section{Article Info}

Article History:

Submitted July 2020

Accepted September 2020

Published March 2021

Keywords:

WHOQOL-BREF, Path

Analysis, Quality of Life, Commuting workers,

KRL Commuter Line,

Psychological Condition

DOI

https://doi.org/10.15294/

kemas.v16i3.25467

\begin{abstract}
Many studies conclude commuting that has an impact on the quality of life of the commuter both in the physical, psychological, health, and environmental aspects of the commuter. Increased risk of musculoskeletal disorder (MSD), obesity, increased blood pressure, and low physical health conditions are found in prolonged commuting activities as the existing problem in public health. This study using cross sectional design with WHO QOL BREF questionnaire. The total sample 155 respondents of commuting working using KRL Commuter Line Bogor to Jakarta in 2018. The initial model for assessing the relationship directly and indirectly between quality of life among commuting workers and travel uncomfortable, health complaint, psychological condition, bad experience, and income was constructed on the basis of severe hypotheses Based on the results of the path analysis it was found that income has a direct effect on quality of life. Psychological conditions have a direct effect on quality of life. Psychological condition is intervening variable for travel uncomfortable and health complaints as indirect effect. These results may help to identify the direct factor to improve the quality of life among commuting workers and as a basis for developing policies to improve the quality of public transportation services for commuting workers, and as a basis for formulating policies related to housing development locations that are integrated with public transportation facilities.
\end{abstract}

\section{Introduction}

Indonesia faces an increase in the number of commuter workers. It was around 6 million commuters in 2011 up $17 \%$ to 7 million in 2014. Basically, commuting has a positive impact on the economy of the destination and area of origin. But it has a negative impact on the quality of life. In addition to the impact of time wasted, transportation costs, and the risk of accidents (Nuvolati G, 2007). Increased risk of musculoskeletal disorder (MSD), obesity, increased blood pressure, and low physical health conditions are found in prolonged commuting activities (Hoehner 2012). Many studies also conclude that commuting has an impact on the quality of life of the commuter both in the physical, mental / psychological, health, and social / environmental aspects of the commuter (Hoehner CM, Barlow CE, \& Allen P, 2016 \& Mattisson K 2015).

The study found that levels of life satisfaction and happiness were lower for commuters who used public transportation than those who did not include commuters (Stutzer \& Frey, 2008) (Gottholmseder, Nowotny, Pruckner, \& Theurl, 2009). Commuter workers are also potentially exposed to Particulate Matter (PM) and Ultrafine Particles (UFPs)

\footnotetext{
$\triangle$ Correspondence Address:

Occupational Health and Safety Program, Faculty of Medicine and Health Science,

pISSN 1858-1196

Universitas Jambi

eISSN 2355-3596
}

Email : kusmawandavid@gmail.com 
(Knibbs, Cole-Hunter, \& Morawska, 2011; Zuurbier et al., 2010), respiratory tract disorders due to air pollution (Zuurbier et al., 2011). Air pollution produces pollutants including particulate matter (PM), carbon monoxide $(\mathrm{CO})$, nitrogen dioxide $(\mathrm{NO} 2)$, volatile organic compounds (VOCs), and polycyclic aromatic hydrocarbons. (PAHs) (Han \& Naeher, 2006).

In addition to physical and psychological impacts, commuting has an impact on social aspects, namely social capital. Commuters tend to limit their free time for social activities and recreation and create negative externalities in society by reducing participatory activities (Sandow, 2011). The phenomenon of commuting related to the quality of life of workers is a problem of public health that must be assessed based on empirical evidence. Research on commuting still revolves around the number, pattern of mobility, and characteristics of commuting. Few studies analyze the link between commuter workers and the health / quality of life of commuters and assess public health and safety aspects. These impacts need to be a concern of the government at this time because the phenomenon of commuter workers in Indonesia has become a daily portrait in major cities in Indonesia, such as Jakarta, Medan, Denpasar, Surabaya, Makassar. In Jakarta-Bogor-Depok-Tangerang- Bekasi in 2014, there were 3.6 million commuters (13\%) out of 28 million people. The majority of them aim to work (commuter workers) which is $82 \%$ (BPS).

The initial model for assessing the relationship directly and indirectly between quality of life among commuting workers and travel inconvenience, health complaint, psychological condition, bad experience, and income was constructed on the basis of severe hypotheses: (H1) travel uncomfortable directly influences quality of life on commuting workers, (H2) health complaint has direct effect to quality of life on commuting workers, (H3) psychological condition affects directly on quality of life on commuting workers, (H4) bad experience has a direct effect to quality of life on commuting workers, (H5) income directly influences to quality of life on commuting workers, (H6) the influence of travel inconvenience on quality of life on commuting workers is mediated by psychological condition, (H7) the influence of health complaint on quality of life on commuting workers is mediated by psychological condition, (H8) the influence of bad experience on quality of life on commuting workers is mediated by psychological condition, (H9) the influence of income on quality of life on commuting workers is mediated by psychological condition.

\section{Method}

This study is part of the research on the quality of life (QOL) of commuting workers who use the KRL Commuter Line and Busway TransJakarta from Bogor to Jakarta in 2018 with WHO QOL BREF questionnaire. The research is funded by The Directorate of Research and Community Engagement of Universitas Indonesia 2018. This study using cross sectional design with a total of 155 respondents of commuting workers using KRL Commuter Line Bogor to Jakarta in 2018. The research questionnaire was approved in regards of ethical studies by the Directorate of Research and Community Service, Faculty of Public Health, Universitas Indonesia with Approval Number 296/UN2.F10PPM.00.02/2018.

A pilot survey involving 30 pre-test subjects has been done to test the validity and reliability of the questionnaire. Then the questionnaire was distributed via Google Form. A brief assessment was conducted and the questionnaire which were answered incompletely were excluded from the study. Finally, 155 completed questionnaires which were qualified to be used in the analysis. As already mentioned briefly, the aim of this study was to construct a path analysis model for assessing the relationship directly and indirectly between quality of life among commuting workers and travel uncomfortable, health complaint, psychological condition, bad experience, and income. In doing this, Lisrel 8.7 was employed. Descriptive analysis was applied to explain the distribution of the answers from respondents for each question. Path analysis is a useful tool for assessing direct and indirect effects of some variables on a specific target variable, which was safety behavior in the present study. The strength of a path is represented by a coefficient conceptually equal 
to standardized partial regression coefficients. A coefficient has a range from -1 to +1 . The higher the coefficient, the greater the effect one variable has on another. In order to assess the significance of a path in a path analysis model, the $t$ value which is the ratio of the unstandardized estimate to standard error is used. If $\mathrm{t}>1.96$, the path is significant at 0.05 . In addition to each path, the goodness of fit of a path analysis model can also be determined using indices available for such evaluations. These indices can be categorized into two main groups: absolute fit indices and comparative fit indices. Absolute fit indices outline how well the hypothesized model fits the data (Hooper D, Coughlan J \& Mullen M, 2008).

The model $\chi^{2}$ value, Root Mean Square Error of Approximation (RMSEA), Goodness of Fit Index (GFI) and Root Mean Square Residual (RMR) are some indices categorized in the group. (Hooper D, Coughlan J \& Mullen $M, 2008)$. The model $\chi 2$ value is very sensitive to the sample size and normally its value increases as the sample size increases. To fix this problem, (6) (Wheaton B, Muthen B, Alwin DF, 1977) proposed that the ratio of the $\chi^{2}$ value to the degree of freedom df should be used so that a ratio lower than two is indicative of a satisfactory model fit. (Hooper D, Coughlan J \& Mullen M, 2008). RMSEA is another absolute fit index, popular because of its sensitivity and informative and easy to interpret nature. This index is calculated using the model $\chi^{2}$ value, $\mathrm{df}$, and sample size (N) (Equation (1)) (Kline $R B, 2015)$ (7). An RMSEA value lower than 0.07 indicates a good fit, values lower than 0.1 are indicative of mediocre fit and values higher than 0.1 represent unacceptable model fit. (Hooper D, Coughlan J \& Mullen M, 2008)

$$
\operatorname{RMSEA}=\sqrt{ }\left(\chi^{2}-\mathrm{df}\right) /(\mathrm{df}(\mathrm{N}-1)),
$$

Where is the RMSEA, root mean square error of approximation, $\chi^{2}$ is the Chi-square value of the model, $\mathrm{N}$ is sample size. (Hooper D, Coughlan J \& Mullen M, 2008)

\section{Results and Discussion}

This study also wanted to know how the description of travel inconvenience, health complaint, psychological condition, bad experience, and income of commuting workers using KRL Commuter Line.

Based on the table above, the highest uncomfortable of travel felt inconvenience by workers using the KRL Commuter line is the crowded conditions with the largest average value of 7.63 (scale 0 -10) while the least accident conditions are felt with the smallest average value of 4.43 (scale of $0-10$ ). In health conditions, the highest complaints experienced were aches with an average value of 7.14 (scale of $0-10$ ). While the least complaints were experienced with nausea with the smallest average value of 3.56 (scale $0-10$ ). In psychological conditions, the highest feeling experienced by commuter line KRL users is uncomfortable perception with an average value of 6.08 (scale $0-10$ ). While the lowest feeling felt is sad with the smallest average value of 4.24 (scale $0-10$ ). In a bad experience, the most experienced events were schedule delays with an average value of 5.81 (scale of $0-10)$ while the events most rarely experienced were accidents with the smallest average value of 1.94 (scale of $0-10$ ).We constructed model based on the assumptions of the study, resulting a model with acceptable fit where $\chi 2$ was 0.000 and df 0 , model fit index $\chi 2 / \mathrm{df}$ was in acceptable level (less than 2). From the model, the RMSEA was also less than 0.07. From the model (Figure 1), it should be stressed that factors affected to quality of life on commuting workers in nine different ways: (1) direct path from travel uncomfortable; (2) direct path from health complaint; (3) direct path from bad

Table 1. Description of Income Among Commuting Workers Using KRL Commuter Line

\begin{tabular}{lcc}
\hline Income (IDR) & Amount & Percentage \\
\hline 3 million -6 million & 56 & 35.9 \\
6 million -9 million & 52 & 33.3 \\
9 million -12 million & 25 & 16.0 \\
$>12$ million & 23 & 14.7 \\
\hline
\end{tabular}

Source: Primary data, 2018 
Table 2. Description of Travel Inconvenience, Health Complaint, Psychological Condition, Bad Experience

\begin{tabular}{|c|c|c|c|c|c|c|}
\hline \multirow{2}{*}{ No } & \multirow{2}{*}{ Variable } & \multicolumn{5}{|c|}{ KRL Commuter line } \\
\hline & & $\mathbf{N}$ & Min & $\operatorname{Max}$ & Mean & Std Dev \\
\hline Code & Travel Inconvenience & & & & & \\
\hline KP 15 & Jostle & 156 & 1 & 10 & 7.63 & 2.15 \\
\hline KP 16 & Schedule delays & 156 & 1 & 10 & 6.92 & 2.52 \\
\hline KP 17 & Noise & 156 & 2 & 10 & 5.73 & 2.02 \\
\hline KP 18 & Air pollution & 156 & 1 & 10 & 5.52 & 2.39 \\
\hline KP 19 & Traffic condition & 156 & 1 & 10 & 5.21 & 2.58 \\
\hline KP 20 & Accident & 156 & 1 & 10 & 4.43 & 2.45 \\
\hline KP 21 & Travelling time & 156 & 1 & 10 & 5.87 & 2.60 \\
\hline & Health Complaint & & & & & \\
\hline KS 22 & Dizzy & 156 & 1 & 10 & 4.20 & 2.45 \\
\hline KS 23 & Nausea & 156 & 1 & 10 & 3.56 & 2.28 \\
\hline KS 24 & Stiff & 156 & 1 & 10 & 7.14 & 2.44 \\
\hline KS 25 & Fatigue & 156 & 1 & 10 & 7.04 & 2.38 \\
\hline KS 26 & Heat exposure & 156 & 1 & 10 & 5.51 & 2.37 \\
\hline & Psychological Condition & & & & & \\
\hline KP 27 & Uncomfortable perception & 156 & 1 & 10 & 6.08 & 2.26 \\
\hline KP 28 & Feeling angry & 156 & 1 & 10 & 5.29 & 2.31 \\
\hline KP 29 & Feeling of stress & 156 & 1 & 10 & 5.20 & 2.56 \\
\hline KP 30 & Feeling sad & 156 & 1 & 10 & 4.24 & 2.45 \\
\hline KP 31 & Feeling of worry & 156 & 0 & 10 & 4.85 & 2.53 \\
\hline & Bad Experiences & & & & & \\
\hline PB 32 & Sexual harassment & 156 & 1 & 10 & 2.37 & 2.30 \\
\hline PB 33 & Lost goods & 156 & 0 & 10 & 2.81 & 2.69 \\
\hline PB 34 & Accident & 156 & 1 & 8 & 1.94 & 1.54 \\
\hline PB 35 & Late schedule & 156 & 1 & 10 & 5.81 & 2.56 \\
\hline
\end{tabular}

Source: Primary data, 2018

Table 3. Description of Quality of Life in Each Domain

\begin{tabular}{lccccc}
\hline Quality of Life Domain & \multicolumn{5}{c}{ KRL Commuter line } \\
\hline Physical Domain & N & Min & Maks & Means & Std dev \\
Psychological Domain & 156 & 31 & 81 & 57.07 & 10.84 \\
Domain of social relations & 156 & 31 & 100 & 67.30 & 12.37 \\
Environment & 156 & 25 & 100 & 66.04 & 16.43 \\
Total Quality of Life & 156 & 44 & 100 & 68.46 & 11.64 \\
\hline
\end{tabular}

Source: Primary data, 2018

experience; (4) direct path from income; (5) mediated by psychological condition; and (9) direct path from psychological condition; (6) indirect path from income which was mediated indirect path from travel uncomfortable which by psychological condition;.

was mediated by psychological condition; (7) The variable affects quality of life in two indirect path from health complaint which different ways; (1) direct effect; (2) the effect was mediated by psychological condition; (8) mediated by psychological condition. As shown indirect path from bad experience which was in the path model, among these variables, 


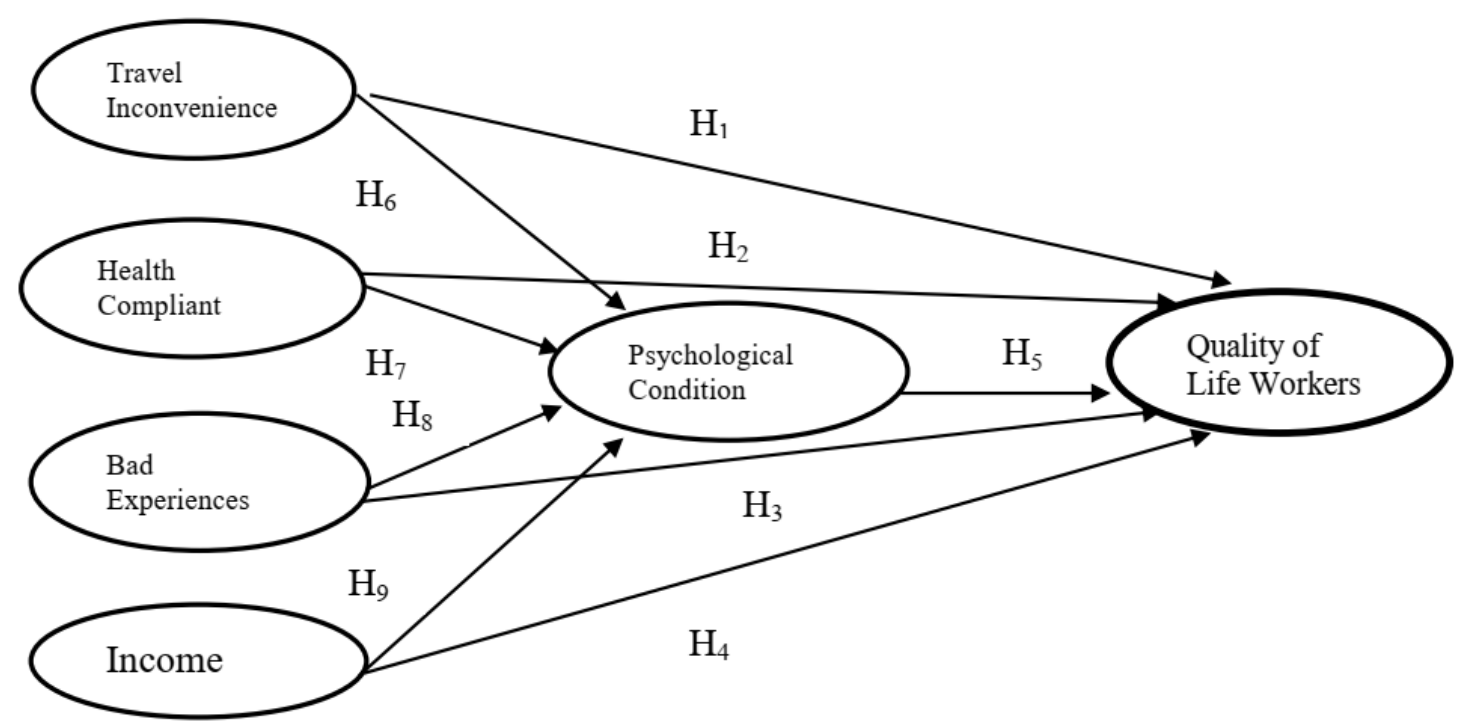

Figure 1. The Path Model for Assessing the Impact of Travel Inconvenience, Health Complaint, Psychological Status, Bad Experience, and Income to Quality of Life on Commuting Workers Using KRL Commuter Line Bogor to Jakarta

psychological condition towards quality of life on commuting workers is the highest impact. Furthermore, for direct effect, psychological condition and income were two variables with a significant influence toward quality of life on commuting workers. Meanwhile, travel inconvenience and bad experience do not influence quality of life on commuting workers directly but it is also shown that travel inconvenience and health complaint have significant indirect effect to quality of life on commuting workers mediated by psychological condition.

Table 3 presents all statistics about each path. From this information and the model in Figure 1, it can be observed that the strongest impact of quality of life directly was psychological condition, followed by income.

Using path analysis model, we are also able to quantify the direct and indirect effects that variables have on each other. Table 4 presents these significance levels of each path in the model of quantities for each variable. As is evident from this table, psychological condition and income toward healthy quality of life was the variable with the highest direct effect. Based on the results of the path analysis it was found that income has a direct effect on quality of life. In cross-sectional studies, high levels of perceived stress were found among people with low socio-economic status as measured by education and level of disability. This may indicate an increased risk of unemployment from perceived stress among people with low socioeconomic levels as compared to those with high socio-economies (Maehlisen, 2018)

Psychological conditions have a direct effect on quality of life. Increased levels of stress and worry can reduce the quality of life of individuals. The level of poor comfort and security that is not guaranteed during travel is a major factor in commuter line KRL not being the main choice in transportation modes. The irritability experienced by individuals not only affects aspects of physical health, but also affects other aspects such as psychological aspects of individuals that can affect the level of quality of life of individuals.

While travel inconvenience and health complaints have an indirect effect on quality of life mediated through psychological conditions. A smooth road condition is a measure that can describe the operational quality of traffic in the form of speed, travel time, freedom of maneuvering, comfort, free vision, road safety and safety. There are several factors of travel conditions or environmental conditions that can affect the quality of life, namely changes 
Table 4. Significance Level of Each Path in the Model

\begin{tabular}{llccc}
\hline Path & To & $\begin{array}{c}\text { Unstandardized } \\
\text { Path Coefficient }\end{array}$ & SE & t \\
\hline From & Psychological condition & $0.228^{*}$ & 0.071 & 1.465 \\
Travel Inconvenience & Psychological condition & $0.405^{*}$ & 0.095 & 2.349 \\
Health complaint & Psychological condition & 0.136 & 0.0701 & 1.947 \\
Bad experience & Psychological condition & -0.018 & 0.0317 & -0.569 \\
Income & quality of life on commuting workers & -0.0331 & 0.142 & -2.605 \\
Travel Inconvenience & quality of life on commuting workers & 0.0175 & 0.095 & 3.245 \\
Health complaint & quality of life on commuting workers & 0.0437 & 0.088 & -2.184 \\
Bad experience & quality of life on commuting workers & $0.140^{*}$ & 0.065 & -1.436 \\
Income & quality of life on commuting workers & $0.249^{*}$ & 0.065 & -1.600 \\
\hline Psychological condition & P & & &
\end{tabular}

Note: ${ }^{*}$ (Significant) if $\mathrm{t}>1,96$

Source: Primary Data, 2018

in business situations, political uncertainty, technological progress, noise, traffic jams and an atmosphere that is not conducive to the journey to work (Robbins, 2006). Exposure to noise caused by the commuter line KRL when crossing on the rails such as engine noise, horns, and friction between the wheels and rails for a long period of time will result in mild hearing loss.

Exposure to noise is a health risk. There is sufficient scientific evidence that noise exposure can cause hearing loss, sleep disturbance. Changes in blood pressure and the risk of ischemic heart disease for other effects such as systolic blood pressure, SBP, diastolic blood pressure, DBP, and heart rate (Tomei G et al., 2010). The average journey of workers using the KRL commuter line from Bogor station is around two hours with a range of one to three hours. This is consistent with the results of a survey conducted by BPS (2012) which found the average commuter worker trip in the Greater Jakarta area was 61 to 120 minutes. Weaknesses of the commuter line KRL service, namely: (1) the number of passengers exceeds the capacity so that the passengers are jostled and squeezed; (2) frequent disruptions caused by infrastructure such as delays in departure schedules; (3) the occurrence of commuter line KRL accidents caused by human negligence. Shorter commute times and decreased working hours can prevent sleep problems in workers (Kim, 2019).

Transportation problems are one of the factors related to the level of quality of life of a person which is influenced by aspects of physical health, psychology and interpersonal relationships. The number of passengers exceeds the capacity causing passengers to jostle and squeeze each other. So that passengers often experience health problems such as dizziness, nausea, aches, colds, and ringing ears. Path analysis is a strong method for evaluating direct and indirect effects, but it has some limitations. Some of these limitations are discussed by (Jeon J, 2015). For examples path analysis can only be used for explanation and not for prediction (Jeon J, 2015). This study's limitation was the use only commuting workers from BogorJakarta. So that this study can be reflect only these workers in this area.

\section{Conclusion}

Based on the results of the path analysis it was found that income has a direct effect on quality of life. Psychological conditions have a direct effect on quality of life. While travel conditions and health complaints have an indirect effect on quality of life mediated through psychological conditions. These results may help to identify the direct factor can be intervening to improve the quality of life among commuting workers using KRL Commuter Line Bogor to Jakarta and as a basis for developing policies to improve the quality of public transportation services for commuting workers, and as a basis for formulating policies related to housing development locations 
that are integrated with public transportation facilities so commute times more shorter and prevent sleep problems in workers.

\section{References}

Gottholmseder, G., Nowotny, K., Pruckner, G. J., \& Theurl, E., 2009. Stress Perception and Commuting. Health economics, 18(5), pp.559-576.

Han, X., \& Naeher, L.P., 2006. A Review of Trafficrelated Air Pollution Exposure Assessment Studies in the Developing World. Environment international, 32(1), pp.106120.

Hoehner, C.M., Barlow, C.E., Allen, P., \& Schootman, M., 2012. Commuting Distance, Cardiorespiratory Fitness, and Metabolic Risk. American Journal of Preventive Medicine, 42(6), pp.571-578.

Hooper, D., Coughlan, J., \& Mullen, M., 2008. Evaluating Model Fit: A Synthesis of the Structural Equation Modelling Literature. In 7th European Conference on Research Methodology for Business and Management Studies, pp.195-200.

Jeon, J., 2015. The Strengths and Limitations of the Statistical Modeling of Complex Social Phenomenon: Focusing on SEM, Path Analysis, or Multiple Regression Models. International Journal of Economics and Management Engineering, 9(5), pp.16341642.

Kariv, D., \& Kirschenbaum, A., 2007. Collective Spatial Perceptions of Men and Women Commuters: Linking Space, Jobs and Activity. J. Hum. Ecol, 22(1), pp.71-82.

Kim, S., Kim, Y., Lim, S.S., Ryoo, J.H., \& Yoon, J.H., 2019. Long Commute Time and Sleep Problems with Gender Difference in WorkLife Balance: A Cross-sectional Study of More than 25,000 Workers. Safety and Health at Work, 10(4), pp.470-475.

Kline, R.B., 2015. Principles and Practice of Structural Equation Modeling. Guilford Publications.

Knibbs, L.D., Cole-Hunter, T., \& Morawska, L., 2011. A Review of Commuter Exposure to Ultrafine Particles and Its Health Effects. Atmospheric Environment, 45(16), pp.26112622.
Künn-Nelen, A., 2016. Does Commuting Affect Health? Health Economics, 25(8), pp.9841004.

Maehlisen, M.H., Pasgaard, A.A., Mortensen, R.N., Vardinghus-Nielsen, H., Torp-Pedersen, C., \& Boggild, H., 2018. Perceived stress as a risk factor of unemployment: a register-based cohort study. BMC Public Health, 18(1), pp. 728-738.

Mattisson, K., Håkansson, C., \& Jakobsson, K., 2015. Relationships between Commuting and Social Capital Among Men and Women in Southern Sweden. Environment and Behavior, 47(7), pp.734-753.

Nuvolati, G., 2007. Commuting and Quality of Life: The Italian Case. In Advancing Quality of Life in a Turbulent World (pp. 55-66). Springer, Dordrecht.

Roberts, J., Hodgson, R., \& Dolan, P., 2011. "It's Driving Her Mad": Gender Differences in the Effects of Commuting on Psychological Health. Journal of Health Economics, 30(5), pp.1064-1076.

Sandow, E., 2011. On The Road: Social Aspects of Commuting Long Distances to Work. Doctoral Dissertation. Kulturgeografiska Institutionen, Umeå Universitet.

Stutzer, A., \& Frey, B.S., 2008. Stress that Doesn't Pay: The Commuting Paradox. The Scandinavian Journal of Economics, 110(2), pp.339-366.

Tomei, G., Fioravanti, M., Cerratti, D., Sancini, A., Tomao, E., Rosati, M.V., Vacca, D., Palitti, T., Di Famiani, M., Giubilati, R., De Sio, S., \& Tomei, F., 2010. Occupational Exposure to Noise and the Cardiovascular System: A Meta-Analysis. Science of the Total Environment, 408(4), pp.681-689.

Urhonen, T., Lie, A., \& Aamodt, G., 2016. Associations Between Long Commutes and Subjective Health Complaints Among Railway Workers in Norway. Preventive Medicine Reports, 4, pp.490-495.

Wheaton, B., Muthen, B., Alwin, D.F., \& Summers, G.F., 1977. Assessing Reliability and Stability in Panel Models. Sociological Methodology, 8, pp.84-136.

Zuurbier, M., Hoek, G., Oldenwening, M., Meliefste, K., van den Hazel, P., \& Brunekreef, B., 2011. Respiratory Effects of Commuters' Exposure to Air Pollution in Traffic. Epidemiology, 2011, pp.219-227. 